\title{
Solvent Extraction of Tungsten(VI) from Moderate Hydrochloric Acid Solutions with LIX 63
}

\author{
Hoai Thanh Truong ${ }^{1}$, Yong Hwan Kim², and Man Seung Lee ${ }^{1, *}$ \\ ${ }^{I}$ Department of Advanced Materials Science \& Engineering, Institute of Rare Metal, Mokpo National University, \\ Jeollanamdo 58554, Republic of Korea \\ ${ }^{2}$ Korea Institute of Industrial Technology, Incheon Technology Service Centre, Incheon 21999, Republic of Korea
}

\begin{abstract}
The solvent extraction of tungsten(VI) from hydrochloric acid solutions using 5,8-diethyl7-hydroxydodecan-6-one oxime (LIX 63) was analyzed in solutions having an initial $\mathrm{pH}$ range from 2 to 5 , by varying the concentration of metal and extractant. In our experimental range, the cationic exchange reaction as well as the solvation reaction occurred simultaneously. The cation exchange reaction was identified by applying a slope analysis method to the extraction data. The existence of cationic tungsten(VI) species was confirmed by ion exchange experiments with Diphonix resin at $\mathrm{pH} 3$. Further study is needed to identify the nature of this tungsten cationic species.
\end{abstract}

(Received November 23, 2016; Accepted January 10, 2017)

Keywords: solvent extraction, ion exchange, tungsten, hydrochloric acid, LIX 63.

\section{INTRODUCTION}

Tungsten is a strategic metal used in many technology fields $[1,2]$. Given the wide range of applications which employ tungsten, processes have been developed to recover tungsten from resources such as alloy scrap [3,4], tungsten or molybdenum ores [5,6], and spent catalysts [7]. Among the various recovery methods, hydrometallurgical processes are frequently used to separate tungsten from leaching solutions of the above resources; to produce tungsten with high purity, solvent extraction is generally employed $[1,8]$.

During our work on the separation of molybdenum(VI), vanadium(V), rhenium(VII) and tungsten(VI) from hydrochloric acid solution, it was found that a small amount of tungsten(VI) and most of the molybdenum(VI) and vanadium(V) was extracted when LIX 63 was used in a solution with a $\mathrm{pH}$ of 2.0 [9]. According to the distribution diagram of molybdenum(VI) and vanadium $(\mathrm{V})$, some types of cationic species, such as $\mathrm{MoO}_{2}{ }^{2+}$ and $\mathrm{VO}_{2}{ }^{+}$, can exist in a solution with a $\mathrm{pH}$ around 2.0, while in an alkaline solution most of them exist as anionic species [10]. The presence of

*Corresponding Author: Man Seung Lee

[Tel: +82-61-450-2492, Email: mslee@mokpo.ac.kr]

Copyright (c) The Korean Institute of Metals and Materials cationic species of molybdenum(VI) and vanadium(V) would be consistent with the high level of extraction of these metals by LIX 63 from an acidic solution with a pH of 2.0.

In general, the distribution of tungsten(VI) in an aqueous solution is very complicated. In alkaline solutions most of the tungsten exists as $\mathrm{WO}_{4}{ }^{2-}$ but various polytungstate anions, such as $\mathrm{W}_{12} \mathrm{O}_{39}{ }^{6-}, \quad \mathrm{W}_{12} \mathrm{O}_{41}{ }^{10-}$, and $\mathrm{W}_{6} \mathrm{O}_{20}(\mathrm{OH})^{5-}$ are predominant in solutions with $\mathrm{pH}$ from 2.0 to 5.0 [11-13]. In stronger acidic solutions, a small fraction of neutral species like $\mathrm{WO}_{2} \mathrm{Cl}_{2}$ can exist [14].

In order to separate the tungsten(VI) from a leaching solution, either amine $[5,12,15]$ or neutral $[14]$ extractants are widely employed. A few studies have reported that cationic tungsten(VI) species can exist in strong acidic solutions, and can be extracted by cationic extractants such as DEHPA $[12,16]$ and LIX 63 [17]. LIX 63 is a chelating reagent containing a selective coordinating group which is advantageous for the separation of cationic metal species and metal in a hydroxide form (M-OH) [17-20]. However, tungsten(VI) is easily precipitated at a $\mathrm{pH}$ less than 2.0 , and for that reason either $\mathrm{H}_{2} \mathrm{O}_{2}$ or acid tartaric is often added to prevent its precipitation $[14,17,21]$.

Although the reactions for the solvent extraction of tungsten by amine and neutral extractants have been 
Table 1. Physico-chemical characteristics of Diphonix resin used in this study.

\begin{tabular}{cccccc}
\hline Resins & $\begin{array}{c}\text { Ionic } \\
\text { forms }\end{array}$ & $\begin{array}{c}\text { Dry mesh } \\
\text { size }\end{array}$ & $\begin{array}{c}\text { Bead size } \\
(\mu \mathrm{m})\end{array}$ & $\begin{array}{c}\text { Capacity } \\
\left(\mathrm{meq} / \mathrm{cm}^{3}\right)\end{array}$ & $\begin{array}{c}\text { Density } \\
\left(\mathrm{g} / \mathrm{cm}^{3}\right)\end{array}$ \\
\hline Diphonix Hydrogen & $100-200$ & $74-150$ & 1.1 & 1.05 \\
\hline
\end{tabular}

identified [14], the reactions of cationic extractants have not been investigated. In this work, solvent extraction experiments were performed to separate tungstern(VI) from hydrochloric acid solutions and to identify the solvent extraction reaction by LIX 63 . The extraction percentage of tungsten(VI) was investigated as a function of initial $\mathrm{pH}$, and the initial concentrations of tungsten and LIX 63. The extraction reaction was identified by applying the slope analysis method to the extraction data and the change in solution $\mathrm{pH}$ after extraction. Moreover, ion exchange experiments were performed to verify the existence of cationic tungsten species.

\section{EXPERIMENTAL}

LIX 63 (supplied by BASF Co., 70\%) was diluted with kerosene (supplied by Samchun Pure Chem. Co., 95\%). A tungsten(VI) solution was prepared by dissolving $\mathrm{Na}_{2} \mathrm{WO}_{4}$ (supplied by Sigma Co., 99\%) in doubly distilled water. The acidity of the solution was adjusted by adding $\mathrm{HCl}$ solution (supplied by Daejung Chemicals and Metals Co., 35\%). Diphonix resin was supplied by Eichrom and used without any pretreatment. The physical and chemical characteristics of this resin are shown in Table 1.

Solvent extraction experiments were carried out by mixing equal volumes $(10 \mathrm{~mL})$ of aqueous and organic phases for 30 min using a wrist action shaker (Burrell. Model 75, USA). After shaking, the aqueous and organic phases were separated using separating funnels. In the case of ion exchange, batch experiments were performed by adding an appropriate amount of resin into the synthetic solution. The samples were shaken in a shaking incubator (HB-201SF, Hanbeak Scientific Co.) for $6 \mathrm{~h}$ at room temperature and then filtered. The metal concentration in the aqueous solution before and after extraction and loading was determined by an inductively coupled atomic emission spectrometer (ICP-AES, OPTIMA

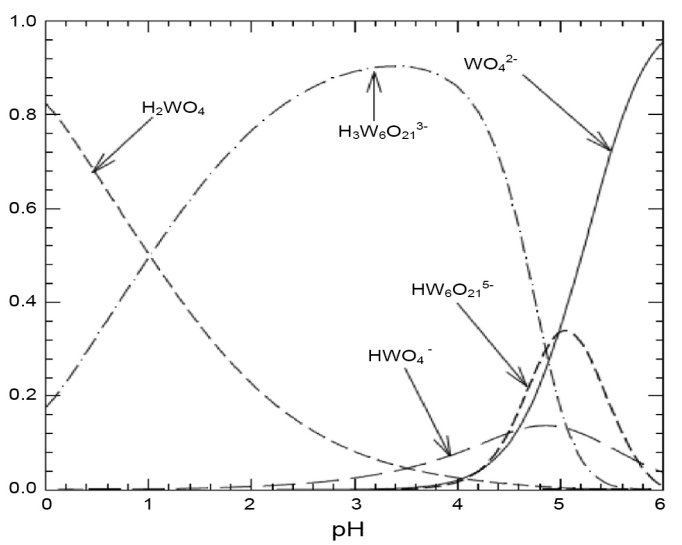

Fig. 1. The variation in the mole fraction of of W(VI) species with solution $\mathrm{pH}$. [W] $=10^{-4} \mathrm{~mol} / \mathrm{L}[13]$.

4300 DV, PerkinElmer Inc., USA). The concentration of metal ions in the loaded organic phase and resin was calculated by mass balance. The initial and equilibrium $\mathrm{pH}$ of the aqueous phase was measured by a $\mathrm{pH}$ meter (Orion Star A211, Thermo Fisher Scientific Inc., USA). The distribution coefficient (D) was calculated as the concentration of metal present in the organic phase to that present in the aqueous phase at equilibrium. The loading percentage was defined as the mass of tungsten(VI) loaded into the resin to the initial mass multiplied by 100 . The extraction percentage was defined as

Extraction percentage $=\frac{\text { Equilibrium mass of metal in the organic }}{\text { Initial mass of metal in the aqueous before extraction }} \times 100$

\section{RESULTS AND DISCUSSION}

\subsection{Effect of solution $\mathrm{pH}$}

In an alkaline solution, tungstate ions $\left(\mathrm{WO}_{4}{ }^{2-}\right)$ exist and polytungstate ions are formed by the polymerization and subsequent splitting of the incorporated water, which is represented as follows [22]

$$
\mathrm{WO}_{4}{ }^{2-}+2 \mathrm{H}^{+}+\mathrm{xH}_{2} \mathrm{O}=\mathrm{H}_{2} \mathrm{WO}_{4} \cdot \mathrm{xH}_{2} \mathrm{O}+\mathrm{WO}_{3} \cdot \mathrm{nH}_{2} \mathrm{O}
$$

Eq. (2) indicates that cationic tungsten species can be formed by ion-ion interactions between the tungstate and 


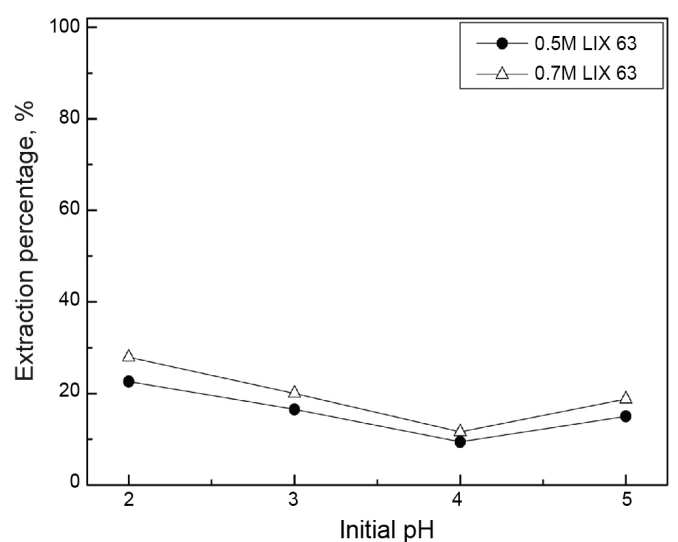

Fig. 2. Effect of initial pH on the extraction of W(VI) by LIX 63. Aqueous: $[\mathrm{W}]=1000 \mathrm{mg} / \mathrm{L}, \mathrm{pH}: 2-5$; [LIX 63] $=0.5$ and 0.7 $\mathrm{mol} / \mathrm{L} ; \mathrm{O} / \mathrm{A}=1$; diluent $=$ kerosene.

hydrogen ions, and the formation reaction can be represented as

$$
\mathrm{WO}_{4}{ }^{2-}+\mathrm{kH}^{+}=\mathrm{HkWO}_{4}{ }^{\mathrm{k}-2}
$$

Figure 1 represents the distribution diagram of tungsten reported in the literature [13]. According to this diagram, neutral species of tungsten(VI), $\mathrm{H}_{2} \mathrm{WO}_{4}$ exist in the $\mathrm{pH}$ range from zero to 3 . When the solution $\mathrm{pH}$ is higher than 1 , anionic tungsten species predominate in the solution.

In the extraction of tungsten(VI) by LIX 63, two solvent extraction reactions can occur. One is the solvation reaction by which anionic tungsten species can be extracted, the other is a cation exchange reaction in which cationic tungsten species is extracted. Eqs. (4) and (5) represent the solvation reaction and cation exchange reaction of tungsten(VI) by LIX 63 , respectively.

$$
\begin{aligned}
& \mathrm{WO}_{4}{ }^{2-}+2 \mathrm{H}^{+}+\text {nHAorg }=\mathrm{H}_{2} \mathrm{WO}_{4} \cdot \mathrm{nHAorg} \\
& \mathrm{HnWO}_{4}{ }^{\mathrm{n}-2}+(\mathrm{n}-2) \mathrm{HA}_{\text {org }}=\mathrm{H}_{\mathrm{nWO}} \mathrm{A} \text { (n-2)org }+(\mathrm{n}-2) \mathrm{H}^{+}
\end{aligned}
$$

where HA represents LIX 63 and $\mathrm{n}$ is the stoichiometric coefficient of LIX 63 involved in the reaction. When the solvation reaction occurs, the equilibrium $\mathrm{pH}$ will be increased, while the equilibrium $\mathrm{pH}$ will be decreased in the extraction of tungsten(VI) by the cation exchange reaction.
Table 2. The change in $\mathrm{pH}$ during extraction of tungsten(VI) by LIX 63.

\begin{tabular}{cccccc}
\hline & Initial $\mathrm{pH}$ & 2.0 & 3.0 & 4.0 & 5.0 \\
\hline \multirow{2}{*}{$\begin{array}{c}\text { Equilibrium } \\
\mathrm{pH}\end{array}$} & $0.5 \mathrm{~mol} / \mathrm{L}$ LIX 63 & 2.0 & 2.9 & 3.3 & 3.5 \\
\cline { 2 - 6 } & $0.7 \mathrm{~mol} / \mathrm{L}$ LIX 63 & 2.0 & 2.9 & 3.2 & 3.5 \\
\hline
\end{tabular}

Aqueous, [W]=1000 mg/L, initial $\mathrm{pH}: 1.98-5.04 ; \mathrm{O} / \mathrm{A}=1: 1$; diluent: kerosene.

In order to identify the solvent extraction reaction of tungsten(VI) by LIX 63, the initial $\mathrm{pH}$ of the hydrochloric acid solution containing tungsten(VI) was varied from 2.0 to 5.0. In these experiments, the concentration of tungsten(VI) was fixed at $1000 \mathrm{mg} / \mathrm{L}$ and two concentrations of LIX 63 $(0.5$ and $0.7 \mathrm{~mol} / \mathrm{L})$ were employed at the unity volume ratio of the two phases. Figure 2 shows the variation in extraction percentage of tungsten(VI) by LIX 63 with solution $\mathrm{pH}$. The extraction percentage of tungsten(VI) decreased when the initial $\mathrm{pH}$ was increased from 2.0 to 4.0 , and then increased again at $\mathrm{pH}$ 5.0. The equilibrium $\mathrm{pH}$ values were lower than the initial $\mathrm{pH}$ in these experiments, indicating that hydrogen ions were transferred to the aqueous phase during the extraction with LIX 63 (See Table 2). Therefore, the change in solution $\mathrm{pH}$ before and after extraction implies that a cationic exchange reaction occurred during the extraction of tungsten(VI) by LIX 63 in our experimental ranges.

In general, the extraction percentage of metals by cationic extractants is increased with solution $\mathrm{pH}$ until a metal hydroxide precipitates. Therefore, the decrease in the extraction percentage of tungsten(VI) as the solution $\mathrm{pH}$ increased from 2.0 to 4.0 may be ascribed to the rapid change in the distribution of tungsten species in these solution $\mathrm{pH}$ ranges. Some studies have demonstrated that a small amount of cationic species like $\mathrm{WO}_{2}{ }^{2+}$ can exist at $\mathrm{pH}$ lower than 2.0 $[12,14,16,17,23,24]$, while polynuclear anionic species are predominant in the solution $\mathrm{pH}$ range of 2.0 to 6.0 [11]. Eq. (3) indicates that a hydrogen ion is necessary to form cationic tungsten(VI) species. Therefore, the fraction of cationic tungsten(VI) species which can be extracted by LIX 63 should be rapidly decreased as solution $\mathrm{pH}$ increases from 2.0 to 5.0. Accordingly, the decrease in the extraction percentage of tungsten(VI) is related to the rapid decrease in the mole fraction of cationic species as solution $\mathrm{pH}$ increases. An 


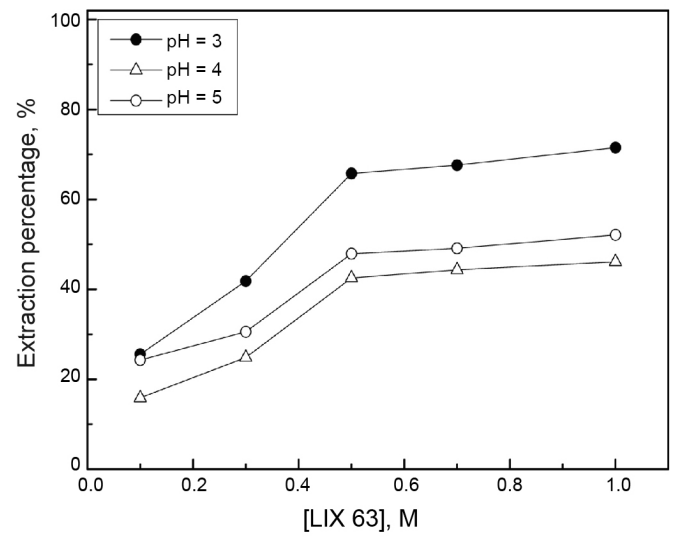

Fig. 3. Effect of LIX 63 concentration on the extraction of W(VI). Aqueous: $[\mathrm{W}]=100 \mathrm{mg} / \mathrm{L}$, initial $\mathrm{pH}=3,4,5$; [LIX 63] $=0.1-$ $1.0 \mathrm{~mol} / \mathrm{L} ; \mathrm{O} / \mathrm{A}=1$; diluent $=$ kerosene.

increase in the extraction percentage as solution $\mathrm{pH}$ is increased from 4.0 to 5.0 might indicate that both the cation exchange and solvation reaction occurred simultaneously under this condition. Although a relatively high extraction percentage of tungsten(VI) was obtained at $\mathrm{pH} 2.0$, the precipitation of tungsten(VI) was observed after holding the solution for several days at room temperature. Therefore, the solution $\mathrm{pH}$ was maintained at 3.0 to prevent the precipitation of tungsten(VI) in further experiments.

The effective equilibrium constant of Eq. (5) can be represented as

$$
\mathrm{K}_{\mathrm{ex}}=\frac{\left[\mathrm{H}_{\mathrm{n}} \mathrm{WO}_{4} \mathrm{~A}_{(\mathrm{n}-2)}\right]\left[\mathrm{H}^{+}\right]^{(\mathrm{n}-2)}}{\left[\mathrm{H}_{\mathrm{n}} \mathrm{WO}_{4}^{(\mathrm{n}-2)}\right][\mathrm{HA}]^{(\mathrm{n}-2)}}
$$

After inserting the definition of the distribution ratio into Eq. (6), rearrangement of the resulting equation leads to

$$
\log \mathrm{D}=\log \mathrm{Kex}_{\mathrm{e}}+(\mathrm{n}-2) \log [\mathrm{HA}]+(\mathrm{n}-2) \mathrm{pH}
$$

where $\mathrm{D}$ represents the distribution coefficient of a metal and is defined as

$$
\mathrm{D}=\frac{\left[\mathrm{H}_{\mathrm{n}} \mathrm{WO}_{4} \mathrm{~A}_{(\mathrm{n}-2)}\right]}{\left[\mathrm{H}_{\mathrm{n}} \mathrm{WO}_{4}^{\left(\mathrm{n}^{-2}\right)}\right]}
$$

The stoichiometric coefficient, $\mathrm{n}$, can be estimated by applying the slope analysis method to the extraction data.

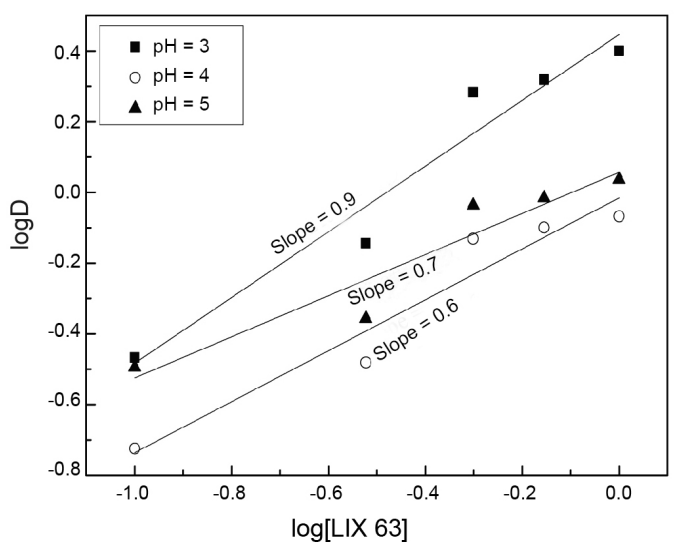

Fig. 4. A plot of $\log \mathrm{D}$ vs $\log [$ LIX 63]. Aqueous: $[\mathrm{W}]=100$ $\mathrm{mg} / \mathrm{L}$, initial $\mathrm{pH}=3 ;$ [LIX 63] $=0.1-1.0 \mathrm{~mol} / \mathrm{L} ; \mathrm{O} / \mathrm{A}=1$; diluent $=$ kerosene.

\subsection{Effect of extractant concentration}

In order to investigate the effect of LIX 63 concentration on the extraction of tungsten(VI), the LIX 63 concentration was varied from 0.1 to $1.0 \mathrm{~mol} / \mathrm{L}$ and the extraction experiments were conducted at a solution $\mathrm{pH}$ of 3.0, 4.0 and 5.0. In these experiments, the concentration of tungsten(VI) was fixed at $100 \mathrm{mg} / \mathrm{L}$. Figure 3 shows the extraction of tungsten(VI) as a function of LIX 63 concentration. The extraction percentage of tungsten(VI) increased from 26 to $72 \%, 16$ to $46 \%$, and 24 to $52 \%$ when LIX 63 was increased from 0.1 to $1.0 \mathrm{~mol} / \mathrm{L}$ at a solution $\mathrm{pH}$ of $3.0,4.0$, and 5.0 , respectively. As shown in Fig. 2, the extraction percentage of tungsten(VI) decreased with the increase in solution $\mathrm{pH}$ from 3.0 to 4.0 , and then increased again at solution $\mathrm{pH}$. The dependence of the extraction percentage on the initial $\mathrm{pH}$ is in good agreement with the data shown in Fig. 2. In order to estimate the stoichiometric coefficient $\mathrm{n}$ in Eq. (7), $\log$ [LIX $63]$ vs. $\log \mathrm{D}$ plots were prepared, and are shown in Fig. 4. The slopes of these plots in Fig. 4 were 0.9, 0.7, and 0.6 at initial solution $\mathrm{pH} 3,4$, and 5. Although the slope decreased when the solution $\mathrm{pH}$ increased from 3.0 to 5.0 , it might be said that one mole of LIX 63 took part in the extraction of one mole of tungsten(VI) ion. Thus, the value of $\mathrm{n}$ in Eq. (5) can be estimated to be 3 , and $\mathrm{H}_{3} \mathrm{WO}_{4}{ }^{+}$seems to be extracted by LIX 63 in our experimental ranges. 
Table 3. Variation in the concentration of hydrogen ion and tungsten(VI) during the extraction with $0.5 \mathrm{~mol} / \mathrm{L}$ LIX 63 at several initial $\mathrm{pH}$ values.

\begin{tabular}{cccccccc}
\hline Ini. pH Eq. pH & $\begin{array}{c}\text { Ex \% of } \\
\text { W(VI) }\end{array}$ & $\mathrm{I}$ & $\gamma_{\mathrm{H}^{+}}$ & $\Delta[\mathrm{W}]$ & $\Delta\left[\mathrm{H}^{+}\right]$ & $\begin{array}{c}\Delta\left[\mathrm{H}^{+}\right] / \\
\Delta[\mathrm{W}]\end{array}$ \\
\hline 1.98 & 1.96 & 27.9 & $1 \times 10^{-2}$ & 0.90 & $1.5 \times 10^{-3}$ & $5.5 \times 10^{-4}$ & 0.36 \\
\hline 2.99 & 2.93 & 20.0 & $1 \times 10^{-3}$ & 0.97 & $1.1 \times 10^{-3}$ & $1.6 \times 10^{-4}$ & 0.14 \\
\hline 3.98 & 3.33 & 11.6 & $1 \times 10^{-4}$ & 0.99 & $0.6 \times 10^{-3} 3.7 \times 10^{-4}$ & 0.58 \\
\hline 5.04 & 3.52 & 18.8 & $1 \times 10^{-5}$ & 1.00 & $1.0 \times 10^{-3}$ & $2.9 \times 10^{-4}$ & 0.29 \\
\hline
\end{tabular}

Ini. $\mathrm{pH}$ : initial $\mathrm{pH}$.

Eq. $\mathrm{pH}$ : equilibrium $\mathrm{pH}$.

$\Delta[\mathrm{W}]$ : the difference in the concentration of tungsten $(\mathrm{V})$ before and after extraction.

Experimental conditions: Aqueous, $[\mathrm{W}]=1000 \mathrm{mg} / \mathrm{L}$, initial $\mathrm{pH}$ : 1.98-5.04; $\mathrm{O} / \mathrm{A}=1: 1$; diluent: kerosene.

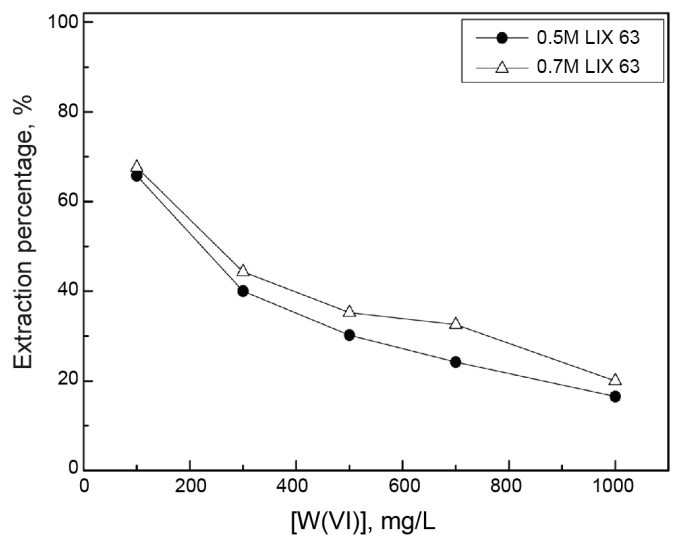

Fig. 5. Effect of metal concentration on the extraction of W(VI) by LIX 63. Aqueous: [W] $=100-1000 \mathrm{mg} / \mathrm{L}$, initial $\mathrm{pH}=3$; [LIX $63]=0.5$ and $0.7 \mathrm{~mol} / \mathrm{L} ; \mathrm{O} / \mathrm{A}=1$; diluent $=$ kerosene

\subsection{Effect of metal concentration}

In order to investigate the occurrence of polymerization in the extracted species in the organic phase, the solvent extraction experiments were conducted with varying tungsten(VI) concentrations from 100 to $1000 \mathrm{mg} / \mathrm{L}$ at a solution $\mathrm{pH}$ of 3.0. In these experiments, two concentrations of LIX $63(0.5$ and $0.7 \mathrm{~mol} / \mathrm{L})$ were employed. Figure 5 shows that with increasing tungsten concentration the extraction percentage of tungsten(VI) decreased from 66 to $17 \%$ and from 68 to $20 \%$ with 0.5 and $0.7 \mathrm{~mol} / \mathrm{L}$ LIX 63 , respectively. In solvent extraction, when the initial concentration of an extractant is fixed, the concentration of

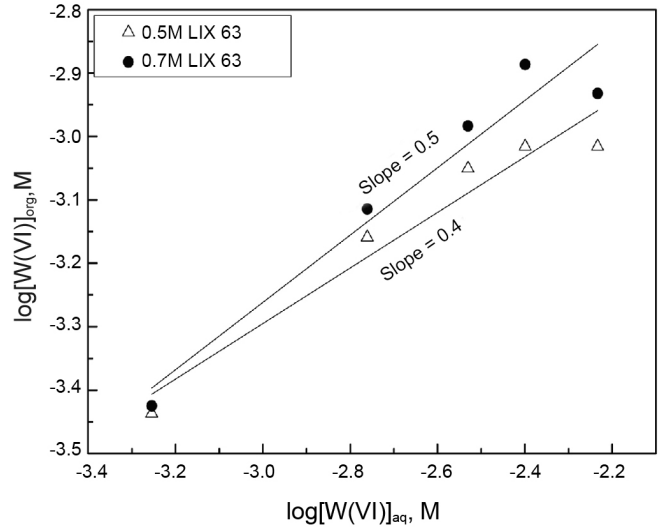

Fig. 6. A plot of $\log [\mathrm{W}(\mathrm{VI})] \mathrm{aq}$ vs $\log [\mathrm{W}(\mathrm{VI})]$ org. Aqueous: [W] $=100-1000 \mathrm{mg} / \mathrm{L}$, initial $\mathrm{pH}=3$; [LIX 63] $=0.5$ and $0.7 \mathrm{~mol} / \mathrm{L}$; $\mathrm{O} / \mathrm{A}=1$; diluent $=$ kerosene.

free extractant is decreased by an increase in the initial concentration of a metal ion in the aqueous phase [25]. Therefore, the extraction percentage of the metal should decrease with increasing metal ion concentration, and this is in good agreement with our data. The plot of $\log [\mathrm{W}(\mathrm{VI})]_{\mathrm{aq}}$ vs. $\log [\mathrm{W}(\mathrm{VI})]_{\text {org }}$ by LIX 63 in these experiments is shown in Fig. 6. The slopes of the log-log plots of the equilibrium concentration of tungsten in the aqueous and organic were 0.4 and 0.5 for 0.5 and $0.7 \mathrm{~mol} / \mathrm{L}$ LIX 63 , indicating that no polymerization of the tungsten species occurred in the organic phase in our experimental ranges. Therefore, the solvent extraction reaction of tungsten(VI) by LIX 63 in the solution $\mathrm{pH}$ range from 3.0 to 5.0 can be represented as

$$
\mathrm{H}_{3} \mathrm{WO}_{4}{ }^{+}+\mathrm{HA}_{\text {org }}=\mathrm{H}_{3} \mathrm{WO}_{4} \text { Aorg }+\mathrm{H}^{+}
$$

\subsection{Analysis of the solvent extraction reaction through the change in solution $\mathrm{pH}$}

Eq. (9) indicates that there is a close relationship between the concentrations of tungsten(VI) and hydrogen ions in the aqueous phase during the extraction with LIX 63 . When tungsten(VI) is extracted only by the cation exchange reaction, one mole of hydrogen ions should be transferred to the aqueous phase with the extraction of one mole of tungsten(VI) ions. In order to check this relation, the data represented in Table 2 was analyzed. From the difference in the initial and equilibrium $\mathrm{pH}$, the change in the concentration 


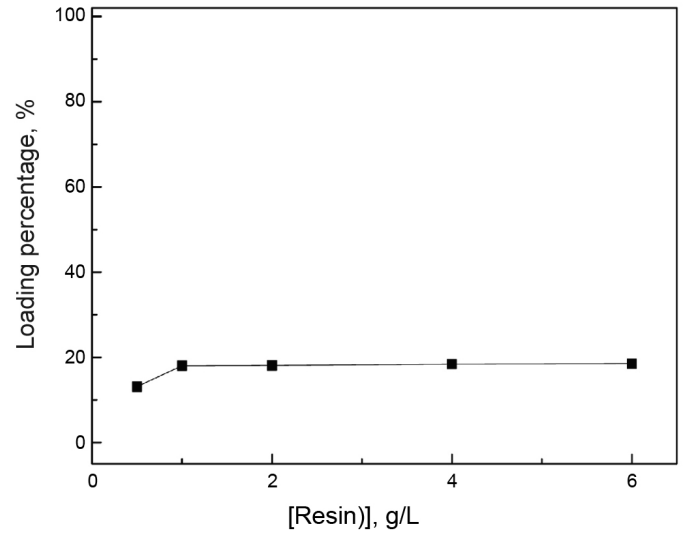

Fig. 7. Effect of resin concentration on the loading of W(VI). Aqueous: $[\mathrm{W}]=100 \mathrm{mg} / \mathrm{L}$, initial $\mathrm{pH}=3$; [Diphonix $]=0.5-6 \mathrm{~g} / \mathrm{L}$.

of hydrogen ions was calculated. Since there is a significant difference in the ionic strength of the $\mathrm{HCl}$ solution as the solution $\mathrm{pH}$ increases from 2.0 to 5.0 , the effect of ionic strength on the activity coefficient of hydrogen ions was considered by employing the Bromley equation, which is represented as [26]

$$
\log \gamma_{\mathrm{H}^{+}}=-\frac{0.5108 \mathrm{I}^{0.5}}{1+\mathrm{I}^{0.5}}+\left[\frac{\left(0.06+0.6 \mathrm{~B}_{\mathrm{HCl}}\right)}{(1+1.5 \mathrm{I})^{2}}+\mathrm{B}_{\mathrm{HCl}}\right] \times\left[\mathrm{Cl}^{-}\right]
$$

In Eq. (10), I is the ionic strength of the solution and $\mathrm{B}_{\mathrm{HCl}}$ is the interaction parameter between $\mathrm{H}^{+}$and $\mathrm{Cl}^{-}$.

The calculated results for hydrogen ions are listed in Table 3 together with the calculated difference in the concentration of tungsten(VI). The data in Table 3 clearly shows that the change in hydrogen concentration was far less than that of tungsten(VI) ion, indicating that not only the cation exchange reaction but also the solvation reaction occurred simultaneously in our experimental conditions. Although the two reactions occurred together, the decrease in solution $\mathrm{pH}$ after extraction clearly indicates that the cation exchange reaction is predominant over the solvation reaction in the extraction of tungsten(VI) by LIX 63.

\subsection{Verification of the existence of tungsten cationic species}

It is difficult to verify the existence of a cationic species by solvent extraction because the solvation reaction can occur. In contrast, only cationic species can be loaded into a cation exchange resin [27]. According to the distribution diagram of tungsten(VI) in hydrochloric acid solution, in the solution $\mathrm{pH}$ range from 2.0 to 5.0 most of the tungsten(VI) exists as anionic species. Therefore, in order to verify the existence of cationic tungsten species in our experimental range, Diphonix resin was employed in this work. First, the concentration of tungsten(V) was fixed at $100 \mathrm{mg} / \mathrm{L}$ and the solution $\mathrm{pH}$ was controlled to 3.0. The concentration of resin in the loading experiments was varied from 0.5 to $6.0 \mathrm{~g} / \mathrm{L}$. The loading percentage of tungsten(VI) is illustrated in Fig. 7. The results indicate that the loading percentage of tungsten(VI) into Diphonix resin increased from 10 to $20 \%$ as the resin concentration increased from 0.5 to $6.0 \mathrm{~g} / \mathrm{L}$. The equilibrium $\mathrm{pH}$ after the loading into Diphonix varied from $2.8 \pm 0.1$, indicating that hydrogen ions were released into the aqueous phase during the ion exchange. Therefore, it can be said that some kind of cationic species exist in the solution $\mathrm{pH}$ range from 2.0 to 5.0 .

Some attempts have been made to explain the structure and nature of the tungsten species in aqueous solution. Most of these experiments were conducted to estimate the stability constants of polytungsten ions [28]. A comprehensive study of tungsten solutions in the $\mathrm{pH}$ range 8 to 15 was carried out by using ${ }^{183} \mathrm{~W},{ }^{17} \mathrm{O}$ and ${ }^{1} \mathrm{H}$ NMR spectroscopy. The results give a new perspective on the formation of tungsten species [29]. Tamhina (1976) and Sato (1995) have used IR spectra to verify the existence of $\mathrm{WO}_{2}{ }^{2+}$ species in aqueous solution after solvent extraction from highly acidic solutions. Thus, further fundamental work is needed to identify the nature of the cationic species in our experimental range.

\section{CONCLUSION}

The solvent extraction of tungsten(VI) from hydrochloric acid solution by LIX 63 was investigated as a function of the initial $\mathrm{pH}$, extractant and metal concentration. The dependence of the extraction of tungsten on solution $\mathrm{pH}$ and the variation in equilibrium $\mathrm{pH}$ indicated that the cation exchange reaction as well as the solvation reaction occurred simultaneously in the initial $\mathrm{pH}$ range from 2.0 to 5.0 . The 
cation exchange reaction of tungsten(VI) by LIX 63 was identified by applying a slope analysis method to the experimental data. Ion exchange experiments with Diphonix resin confirmed that cationic species of tungsten(VI) existed in the solution with an initial $\mathrm{pH}$ of 3.0 .

\section{ACKNOWLEDGMENT}

This work was supported by the Global Excellent Technology Innovation of the Korea Institute of Energy Technology Evaluation and Planning (KETEP), granted financial resource from the Ministry of Trade, Industry \&Energy, Republic of Korea (No.20165010100880). We express sincere thanks to the Korea Basic Science Institute (KBSI), Gwangju branch for providing ICP-OES data.

\section{REFERENCES}

1. T. H. Nguyen and M. S. Lee, Geosystem Eng. 19, 247 (2016).

2. Y. Liu, H. S. Jeon, and M. S. Lee, Met. Mater. Int. 21, 944 (2015).

3. L. Luo, T. Miyazaki, A. Shibayama, W. Yen, and T. Fujita, Miner. Eng. 16, 665 (2003).

4. L. Luo, L. kejun, A. Shibayama, W. Yen, T. Fujita, O. Shindo, and A. Katai, Hydrometallurgy 72, 1 (2004).

5. A. G. Kholmogorov and O. N. Kononova, Hydrometallurgy 76, 37 (2005).

6. T. H. Nguyen and M. S. Lee, Ind. Eng. Chem. 53, 8608 (2014).

7. J. W. Kim, W. G. Lee, I. S. Hwang, J. Y. Lee, and C. Han, J. Ind. Eng. Chem. 28, 73 (2015).

8. M. S. Lee and J. G. Ahn, Korean J. Met. Mater. 53, 488 (2015).
9. H. T. Truong, T. H. Nguyen, and M. S. Lee, Hydrometallurgy (Submitted).

10. L. Zeng and C. Y. Cheng, Hydrometallurgy 98, 10 (2009).

11. P. Nekovárr and D. Schrötterová, Chem. Eng. J. 79, 229 (2000)

12. J. Coca, V. F. Dicz, and M. A. Moris, Hydrometallurgy 25, 125 (1990)

13. T. Nakaruma, S. Nishihama, and K. Yoshizuka, Solvent Extr. Res. Dev. Jpn. 16, 47 (2009).

14. T. Sato and K. Sato, Hydrometallurgy 37, 253 (1995).

15. R. A. Carvolho and M. N. M. Sampaio, Hydrometallurgy 26, 137 (1991).

16. N. R. Das, B. Nandi, and S. N. Bhattacharyya, Anal. Chim. Acta 159, 255 (1984).

17. M. H. H. Mahmoud, S. Nakamura, and K. Akiba, Solvent Extr. Ion Exch. 14, 203 (1996).

18. T. H. Nguyen and M. S. Lee, Hydrometallurgy 155, 51 (2015)

19. S. H. Min and M. S. Lee, Korean J. Met. Mater. 53, 51 (2015).

20. L. Y. Wang, H. Y. Lee, and M. S. Lee, Met. Mater. Int. 21, $166(2015)$

21. W. Guan, G. Zhang, and C. Gao, Hydrometallurgy 127-128, 84 (2012).

22. F. Habashi, $2^{\text {nd }}$ edition, Laval University, Quebec City, p.613 (1999).

23. F. Esnault, M. Robaglia, J. M. Latard, and J. M. Demarthe, The international Solvent Extraction Conference, Lyon (1974).

24. B. Tamhina and M. J. Herak, J. Inorg. Nucl. Chem. 39, 391 (1977).

25. J. Rydberg, M. Cox, C. Musika, and G. R. Choppin, $2^{\text {nd }}$ edition, Marcel Dekker, (1992).

26. J. F. Zamaitis, D. M. Clark, M. Rafal, N. C. Scrivner, American Institute of Chemical Engineers, p.99 (1986).

27. Dr. Inamuddin and M. Luqman, Springer Dordrecht Heidelberg London New York (2012).

28. J. J. Cruywagen, A. G. Draaijer, J. B. B. Heyns, and E. A. Rohwer, Inorganica Chimica Acta 331, 322 (2002).

29. J. J. Hastings and O. W. Howarth, J. Chem. Soc. Dalton Trans. 2, 209 (1992). 